\title{
Correlates of device-measured physical activity, sedentary behaviour and sleeping in children aged 9-11 years from Chile: ESPACIOS study \\ Factores asociados con actividad física, conducta sedentaria y sueño medidos con acelerómetros en niños de 9-11 años de Chile: estudio ESPACIOS
}

Nicolas Aguilar-Farias, Pia Martino-Fuentealba, Damian Chandia-Poblete

Universidad de La Frontera (Chile)

\begin{abstract}
Background: Little is known about of correlates of physical activity (PA), sedentary behaviour (SB), and sleeping in children from Latin America. The aim of this study was to assess the association between potential correlates with device-measured PA, SB and sleeping time in children from 9 to 11 years in Carahue, Chile. Methods: A cross-sectional study was conducted to assess correlates of physical behaviours (demographic, psychological, behavioural, home and school environment factors) from data reported by participants and caregivers. Each participant wore an ActiGraph GT3X+ accelerometer on the hip during seven consecutive days to measure PA, SB and sleeping time. Results: In total, 148 participants completed the study (47.3\% male, $10.0 \pm 0.8$ years). SB was positively associated with age, being female, family income, total screen time and distance to places, and negatively with higher scores of parent support for PA. Light PA was associated with age, family income, total screen time (all negative), and parent support for PA (positive). Moderate PA was associated with being male, self-efficacy and established healthy lifestyle committee at school. Vigorous PA was associated with being male, self-efficacy (both positive) and BMI z-score (negatively). Sleeping time was associated with age, portable videogame ownership (both negative) and PE minutes/week (positive).Conclusion: Variables from different levels explained each behaviour, reinforcing the need for multilevel strategies for promoting and helping to ensure healthier lifestyles in children.
\end{abstract}

Keywords: physical inactivity, sleeping, sitting, sedentary, physical behaviours.

Resumen. Antecedentes: se sabe poco sobre los correlatos de la actividad física (PA), el comportamiento sedentario (SB) y el sueño en niños de América Latina. El objetivo de este estudio fue evaluar la asociación entre los posibles correlatos con la PA, la SB y el tiempo de sueño medidos con acelerómetro en niños de 9 a 11 años en Carahue, Chile. Métodos: se realizó un estudio transversal para evaluar los correlatos de los comportamientos físicos (factores demográficos, psicológicos, de comportamiento, del entorno escolar y del hogar) a partir de los datos informados por los participantes y los cuidadores. Cada participante usó un acelerómetro ActiGraph GT3X + en la cadera durante siete días consecutivos para medir la PA, SB y el tiempo de sueño. Resultados: En total, 148 participantes completaron el estudio (47.3\% hombres, $10.0 \pm 0.8$ años). SB se asoció positivamente con la edad, el hecho de ser mujer, el ingreso familiar, el tiempo total de la pantalla y la distancia a los lugares, y negativamente con puntuaciones más altas de apoyo de los padres para PA. La PA liviana se asoció con la edad, el ingreso familiar, el tiempo total de la pantalla (todo negativo) y el apoyo de los padres para la PA (positivo). La PA moderada se asoció con ser hombre, autoeficacia y un comité de estilo de vida saludable establecido en la escuela. La PA vigorosa se asoció con ser hombre, autoeficacia (ambos positivos) y puntaje BMI (negativo). El tiempo de sueño se asoció con la edad, la propiedad de los videojuegos portátiles (ambos negativos) y los minutos / semana de PE (positivo).Conclusión: las variables de diferentes niveles explicaron cada comportamiento, lo que refuerza la necesidad de estrategias multinivel para promover y ayudar a garantizar estilos de vida más saludables en los niños.

Palabras claves: inactividad física, sueño, tiempo sentado, sedentarismo, conductas físicas.

\section{Introduction}

The benefits in children's health and quality of life associated with physical activity (PA) (Poitras et al., 2016), reduced time spent in front of screens and sedentary (Saunders \& Vallance, 2017) and good sleep (Chaput et al., 2016), as well as the combinations of these behaviours (Sampasa-Kanyinga et al., 2017; Saunders et al., 2016), have been strongly documented in the last years. Current recommendations for school-aged children include doing at least 60 minutes per day of moderate-to-vigorous physical activity (MVPA) (World Health Organization, 2010), spending less than 2 hours per day in front of screens (TV, computers) (Carson, Tremblay, Spence, Timmons, \& Janssen, 2013), and sleeping between 9 to 11 hours per night (M. S. Tremblay et al., 2016). Even in some countries, such as Canada and Australia, have recommendations for these three behaviours through 24-hour movement guidelines for early years (Okely

Fecha recepción: 25-02-19. Fecha de aceptación: 14-06-19

Nicolas Aguilar-Farias

nicolas.aguilar@ufrontera.cl et al., 2017), children and youth (M. S. Tremblay et al., 2016).

To overcome the high global prevalences of physical inactivity, sedentary behaviour (SB) and lack of sleep in children, it is necessary to better understand and identify potential causes or mediators in different contexts (Atkin, van Sluijs, Dollman, Taylor, \& Stanley, 2016). Several correlates have been described in the literature for PA at different intensities, sedentary and screen time, and sleeping time (Chaput et al., 2015; Sterdt, Liersch, \& Walter, 2014; Wilkie, Standage, Gillison, Cumming, \& Katzmarzyk, 2018; Yao \& Rhodes, 2015). However, these behaviours are influenced by a vast diversity of factors that change depending on the setting (Chaput et al., 2015; Hale \& Guan, 2015; Mark S. Tremblay et al., 2016). Measurement methods have advanced allowing better and more feasible ways to assess physical behaviours in free-living environments, but few studies have been conducted in Latin America due to different factors such as related costs, political priorities and lack of research training and capacities, for example (Mark S. Tremblay et al., 2016).

Despite being a very high-income country, Chile has been lagging in several indicators related to PA and SB compared 
with other countries (Aubert et al., 2018), while figures about sleeping time are lacking (Aguilar-Farias, Miranda-Marquez, et al., 2018). Chilean adolescents, for example, are among the most inactive and those with the most substantial differences between boys and girls for PA in the Latin American and Caribbean Region (Aguilar-Farias, Martino-Fuentealba, et al., 2018). However, little is known about potential correlates when these behaviours are objectively measured (AguilarFarias et al., 2016). Furthermore, most available evidence has been obtained from adolescents (Aguilar-Farias et al., 2016), presenting a considerable gap in the literature for those aged under 12 (Aguilar-Farias, Miranda-Marquez, et al., 2018). By identifying potential correlates in this age group and specific contexts within Chile, more feasible and realistic interventions may be designed to overcome this dramatic problem. For this reason, the purpose of this study was to assess the association between potential individual, social and environmental correlates with different intensities of PA, SB and sleeping time as measured with an accelerometer in children from 9 to 11 years in Carahue, Chile. Comparisons of average PA, SB and sleeping time according to sex and day of the week (weekday/weekend) were also included in this study.

\section{Methods}

A cross-sectional study was conducted in children aged 9-11 years from schools in Carahue, Chile. The sample size was determined considering a cross-sectional design with clusters under the following assumptions (Dean, Sullivan, \& Soe, 2013): 1) proportion of children meeting PA recommendations of 50\% (Sampasa-Kanyinga et al., 2017), 2) participants would be sampled in school clusters with an average of 20 students per class, 3) 80\% power, 4) within intra-class correlation of 0.026 (Williamson et al., 2012), 5) $20 \%$ rejection to produce a sample size of 231 participants.

Schools were stratified by type (public/subsidised or private) and then randomly selected. The number of classes to be selected per school was proportional to the total amount of students per site. Then in every school, $4^{\text {th }}$ to $6^{\text {th }}$-grade classes were randomly selected to recruit participants. After a study site was selected, its school principal was contacted to request permission to conduct the procedures. Parents or main caregivers signed informed consent and children signed an assent for participation in the study. Participants were measured in the school settings, while a demographic and family health questionnaires were submitted on a sealed envelope to parents or main caregiver to be completed in their homes. The study was approved by the Scientific Ethics Committee of the Universidad de La Frontera (094/2015 CEC).

\section{Outcome variables}

Each participant was asked to wear an ActiGraph GT3X+ accelerometer (AG; ActiGraph, Pensacola, Florida, USA) attached to an elastic belt on the right hip during 24 hours for seven consecutive days. Children were asked to remove the AG during water-based activities (showering or swimming).

Accelerometer data were downloaded, filtered and extracted using ActiLife v6.13.3 (ActiGraph, Pensacola, Florida, USA). First, an automated filter for detecting time spent sleeping was applied (Barreira et al., 2015). Then, a filter for detecting non-wear periods was applied considering 60 consecutive minutes of zero activity counts (Aadland, Andersen, Anderssen, \& Resaland, 2018). The remaining data were identified as waking wear time. Accelerometer data were considered valid for analysis if participants wore the AG for e»10 waking hours on at least 4 days including a weekend day (Tudor-Locke et al., 2015). Physical behaviours were classified using AG cut-points for the vertical axis developed by Evenson (Evenson, Catellier, Gill, Ondrak, \& McMurray, 2008) as follow: sedentary behaviour (SB, 0-25 counts/15 s), light PA(LPA, 26-573 counts/15 s), moderate PA(MPA, 574-1002 counts/15s), vigorous PA(VPA, e»1003 counts/15 s) and moderate-to-vigorous (MVPA, e»574 counts/15 s). These uniaxial cut-points were preferred as previous studies have reported better accuracy when compared with other methods (Zhu, Chen, \& Zhuang, 2013) as well as this option favours comparability with other studies with similar age groups (Katzmarzyk et al., 2013; Wilkie et al., 2018).

\section{Independent variables}

Potential correlates were selected base on previous evidence (Katzmarzyk et al., 2013; Sterdt et al., 2014; Yao \& Rhodes, 2015) and classified according to the socioecological model (Sallis et al., 2006) as follow: demographic, psychological, behavioural, home and school environment factors.

\section{Demographic and anthropometric}

The participant's main caregiver reported sex, ethnicity and date of birth of their child. Age was calculated based on the participant's date of birth and the day of data collection. In the school visit, height in meters (Seca 213, Hamburg, Germany) and weight in kilograms (Tanita TBF-300A, Tokyo, Japan) were measured to estimate body mass index (BMI, body mass/height ${ }^{2}$ ) and BMI z-score for age and sex using WHO growth reference data (de Onis et al., 2007).

\section{Psychological}

All participants answered a lifestyle questionnaire during the school visit that included questions for several domains. Self-efficacy for PA(8 items) (Motl et al., 2000) and Motivation for PA(5 items) (Mullan, Markland, \& Ingledew, 1997) were measured using validated questionnaires that include questions about how much the children agreed/disagreed with different statements (e.g. 'I can be physically active during my free time on most days'). Every response was coded on a scale of 0 (disagree a lot) to 4 (agree a lot) to calculate the mean score for each questionnaire independently. Health-related quality of life (HRQoL) was measured using the KIDSCREEN-10 (Ravens-Sieberer et al., 2010). The questionnaire comprises 10 questions related to respondents' PA, energy and fitness, moods and emotions, social and leisure participation, social and family relationships, cognitive capacity, and school experience. Every response was coded on a 5-point scale and reversed when necessary to ensure that greater scores indicate better HRQoL. Items for each participant were summed and used to calculate Rasch person-variables, which subsequently were transformed into 
T values with a mean of 50 and a SD of approximately 10.(The KIDSCREEN Group Europe, 2006) The internal consistency was adequate for the questionnaire of self-efficacy (Cronbach's alpha coefficient $(\alpha)$ : 0.74 ) and HRQoL ( $\alpha$ : 0.77 ), while the «Motivation for PA questionnaire» showed a poor internal consistency ( $\alpha$ : 0.36) in this sample (Kline, 2013; Streiner, 2003).

\section{Behavioural}

The following variables were collected through selfreport. Total screen time per day was estimated using two components (television (TV) viewing and videogames or computer/tablet/mobile phone use) with questions from the US Youth Risk Behavior Surveillance System (U.S. Centers for Disease Control and Prevention, 2017). Participants were asked how many hours had spent watching TV on both school and weekend days in the past week. The answers were coded as: I did not watch TV (0); $<1$ hour (0.5); 1 hour (1); 2 hours (2); 3 hours (3); 4 hours (4); $\geq 5$ hours (5). Average TV viewing was calculated using the formula: (TV viewing on school day $\times 5+$ TV viewing on the weekend $\times 2$ )/7. A similar question was used for estimating time spent playing videogames or using a computer/tablet/mobile phone for non-related school work (i.e. social networks) during both school and weekend days. The answers were coded as: I did not play video/computer games or use a computer other than for school work (0); $<1$ hour (0.5); 1 hour (1); 2 hours (2); 3 hours (3); 4 hours (4); $\geq 5$ hours (5). Average computer use was calculated using the formula: (Videogames or computer use on school day $\times 5+$ Videogames or computer/tablet/ mobile phone use on the weekend $\times 2$ )/7. TV viewing and videogames or computer/tablet/mobile phone use were added to estimate total screen time on both school and weekend days, respectively. Then, the average screen time was calculated using the formula: (screen time on school day x 5 + screen time on weekend x 2)/7. Participants were classified as meeting screen time guidelines if they spent less than 2 hours on screens (TV + videogames/computer) per day (Tudor-Locke et al., 2015). The same cut-point ( $\geq 2$ hours per day) was used to classify participants as exceeding TV watching time and videogames or computer use on an average day. To estimate outdoor time, children were asked to report separately how much time they spent outside before school, after school before bedtime and on a weekend day during the past week (Katzmarzyk et al., 2013). Overall outdoor time was calculated as (outdoor time on weekdays (before and after school) x $5+$ (outdoor time on weekend days x 2)/7. Sports participation was defined as participated in sports teams during the past year (yes/no) (Katzmarzyk et al., 2013). Questions for determining active transportation to school asked how they travelled to and from school in the last week (Katzmarzyk et al., 2013). Active transport modes were: walking, bicycle, rollerblade, skateboard and scooter, while passive modes included: bus, minibus, collective taxi, car or motorbike. Days of physical education (PE) were estimated using a single question that asked how many days they had physical education classes in the last week (U.S. Centers for Disease Control and Prevention, 2017). Then, participants were classified into two categories: $1 \mathrm{PE}$ day per week or e» 2 PE days per week.

\section{Home environment}

The participant's primary caregivers were asked to provide information on their educational level, family income, parental support for PA and some screen-based technologies available at home. Educational levels for both the mother and father were classified into four categories (primary, secondary, university degree, postgraduate) based on their last completed course. Family income was obtained from the combined monthly income for their household to be classified into three categories (USD $<450$ (minimum Chilean salary), USD 450-1000 and USD>1000). Parental support for PA was using a questionnaire that asked how often in a typical week they or another adult at home: 1) watch their child participate in PA or sport, 2) encourage their child to do sport or PA, 3) provide transport to sports/PA clubs, and 4) how often they do sport or PA with their child.(Saelens et al., 2012) Responses were coded as follow: never (0), 1-2 days (1), 3-4 days (2), 5-6 days (3) or every day (4), and the mean score was calculated for each participant. The internal consistency for the parental support for PA in this sample was 0.77 (Kline, 2013; Streiner, 2003).

The primary caregivers were asked, with a simple ‘yes' or 'no' question, if their child had the following electronic devices in their room: TV, computer or videogame console. In case they had TV, they were asked about the number of televisions in their home. Also, they were asked if their child owned a mobile phone or portable videogame console.

\section{Neighbourhood environment}

Parents or guardians were asked to a set of questions related to neighbourhood collective efficacy (defined as social cohesion among neighbours combined with their willingness to intervene on behalf of the common good) that included 'Social cohesion and trust' and 'Informal social control' (Sampson, Raudenbush, \& Earls, 1997). First, the participant's caregiver answered five questions that represented 'Social cohesion and trust' on a 5-point scale on how strongly they agreed that 1 ) «people around here are willing to help their neighbours,» 2) «this is a close-knit neighbourhood,» 3) "people in this neighbourhood can be trusted,» 4) «people in this neighbourhood generally don't get along with each other,» and 5) «people in this neighbourhood do not share the same values, attitudes or beliefs» (the last two statements were reverse coded).(Sampson et al., 1997) Similarly, 'Informal social control', expressed as the willingness to intervene for the common good and well-being of the neighbourhood (Sampson et al., 1997), was measured with a 5-item Likerttype scale. The main caregivers were asked about the likelihood (from very unlikely to very likely) that their neighbours could react or be counted on to intervene if: 1) children were skipping school and hanging out on a street corner, 2) children were spray-painting graffiti on a local building, 3) children were showing disrespect to an adult, 4) a fight broke out in front of their house, and 5) the fire or police station closest to their home was threatened with budget cuts. Individual averages were calculated for both 'Social cohesion and trust' and 'Informal social control', and also, the two scales were combined into a single measure of 'Neighbourhood collective efficacy' (Sampson et al., 1997). 
The internal consistency for the collective efficacy ( $\alpha$ : 0.79) and informal social control ( $\alpha: 0.81)$ were adequate, while the social cohesion and trust was lower ( $\alpha$ : 0.64) (Streiner, 2003). The participant's caregivers answered questions about neighbourhood built environment through the NEWS-Y (walkability) (Rosenberg et al., 2009) and questions derived from the Neighbourhood Impact on Kids study survey (distance to places) (Frank et al., 2012; Saelens et al., 2012). These tools assessed the suitability of the neighbourhood environment for walking and performing PA, and the distance to various places such as commercial areas or where a child can be physically active (Frank et al., 2012; Katzmarzyk et al., 2013). Scores for these variables ranged from 0 to 4 . The internal consistency for walkability was 0.71 and distance to places 0.90 (Kline, 2013; Streiner, 2003).

\section{School environment}

The school-level environment was assessed with a tool completed by the school principal or administrator that included questions related to: 1) the availability of school policies from promoting PA or/and healthy eating, 2) presence of established committee for promoting healthy lifestyle at school, 3) proportion of students attending extracurricular sport/PA activities, 4) competitive and non-competitive sport options at school, 5) frequency of physical education and breaks, 6) strategies for promoting active transportation to/ from school, and 7) knowledge about PA recommendations for children and adolescents (Katzmarzyk et al., 2013).

\section{Statistical analysis}

All analyses were conducted in Stata 15.1 (Stata Corp LLC, Texas, USA). Central tendencies are presented as mean (standard deviation) or median (25th-75th percentiles) based on distributional properties. Categorial variables are presented as percentages. A descriptive analysis was conducted for those participants with complete data for accelerometry and all correlates. All potential correlates and physical behaviours (SB, LPA, MPA, VPA, MVPA, sleeping) were compared according to sex. Comparisons between week and weekend days by sex were also conducted for all physical behaviours. Student's t-test and Mann-Whitney test were used for parametric and non-parametric data, respectively. Simple multilevel linear regression was used to analyse associations between each potential correlate (independent variable) and the different physical behaviours. Schools were nested and treated as random effects in all models. Age, sex, income and accelerometer wear time were included as covariates in all models. To assess potential correlates, variables associated with a physical behaviour at $\mathrm{p}<0.10$ were included in the final multiple multilevel linear regression models. This criterion was used to avoid relevant variables from being excluded from the analysis. The potential correlates were entered following this order: demographic, psychological, behavioural, home environment, neighbourhood environment and school environment. Stepwise estimation was conducted where those variables with a p-value $>0.05$ were removed before entering new variables from the following level or domain. In the case that more than one variable was nonsignificant, the variable with the highest $\mathrm{p}$-value was removed first. The process was repeated on each level until only significant variables $(\mathrm{p}<0.05)$ were left.

\section{Results}

In total, six schools and 258 participants were assessed in the study, but 148 were included in the final analysis. 10 participants were excluded due to age range (younger than 9 years old $=1$, and older than 11 years old $=9$ ). Other participants were not included due to invalid data. Sources of invalid data for this study were: an insufficient number of valid accelerometer days and incomplete reports from parents $(n=44)$, only insufficient accelerometer data $(n=36)$ and only incomplete information from parents $(n=20)$.

\begin{tabular}{|c|c|c|c|c|}
\hline Variable & $\begin{array}{c}\text { Total } \\
(\mathrm{n}=148)\end{array}$ & $\begin{array}{c}\text { Boys } \\
(\mathrm{n}=70)\end{array}$ & $\begin{array}{c}\text { Girls } \\
(\mathrm{n}=78)\end{array}$ & $\mathbf{p}$ \\
\hline \multicolumn{5}{|l|}{ Demographic } \\
\hline Age in years, mean (SD) & $10.0(0.82)$ & $10.1(0.80)$ & $9.96(0.83)$ & 0.177 \\
\hline \multicolumn{5}{|l|}{ Nutritional status (\%) } \\
\hline Normal & 33.1 & 34.3 & 32.1 & 0.739 \\
\hline Overweight & 42.6 & 44.3 & 41.0 & \\
\hline Obesity & 24.3 & 21.4 & 26.9 & \\
\hline BMI z-score & $1.8(0.97)$ & $1.9(0.98)$ & $1.6(0.96)$ & 0.125 \\
\hline Ethnic group (\% mapuche) & 37.8 & 41.4 & 34.6 & 0.394 \\
\hline \multicolumn{5}{|l|}{ Psychological } \\
\hline Self-efficacy score (range 0-4, mean (SD)) & $2.6(0.84)$ & $2.7(0.82)$ & $2.5(0.85)$ & 0.120 \\
\hline Motivation for PA (range 0-4, mean (SD)) & $2.4(0.72)$ & $2.2(0.65)$ & $2.5(0.74)$ & 0.007 \\
\hline HRQoL (T score, mean (SD)) & $48.3(11.51)$ & $47.8(11.51)$ & 48.7 (10.95) & 0.618 \\
\hline \multicolumn{5}{|l|}{ Behavioral } \\
\hline $\begin{array}{l}\text { Screen time (h/day, mean (SD)) } \\
\text { s. }\end{array}$ & $3.1(2.20)$ & $3.0(2.30)$ & $3.3(2.11)$ & 0.346 \\
\hline TV viewing (h/day, mean (SD)) & $1.8(1.26)$ & $1.7(1.25)$ & $2.0(1.26)$ & 0.099 \\
\hline Videogames/computer use (h/day, mean (SD)) & $1.3(1.37)$ & $1.3(1.35)$ & $1.3(1.39)$ & 0.998 \\
\hline Outdoor time (h/day) & $3.3(2.15)$ & $3.6(2.20)$ & $3.0(2.09)$ & 0.154 \\
\hline Sport participation (\% yes) & 59.5 & 75.7 & 44.9 & $<0.00$ \\
\hline \multicolumn{5}{|l|}{ Active transportation to school (\% yes) } \\
\hline Walking or cycling & 37.8 & 40.0 & 35.9 & 0.607 \\
\hline Walking & 34.5 & 37.1 & 32.0 & 0.515 \\
\hline Cycling (cycles) & 3.4 & 2.9 & 3.9 & 0.740 \\
\hline \multicolumn{5}{|l|}{ Physical education (\%) } \\
\hline$<2$ classes per week & 16.2 & 18.6 & 14.1 & 0.461 \\
\hline \multicolumn{5}{|l|}{ Home environment } \\
\hline \multicolumn{5}{|l|}{ Mother's educational level (\%) } \\
\hline Primary education & 24.3 & 27.1 & 21.8 & 0.675 \\
\hline Secondary education & 54.7 & 50.0 & 59.0 & \\
\hline University degree & 17.6 & 20.0 & 15.4 & \\
\hline Postgraduate & 3.4 & 2.9 & 3.8 & \\
\hline \multicolumn{5}{|l|}{ Father's educational level (\%) } \\
\hline $\begin{array}{l}\text { Primary education } \\
\text { Pos }\end{array}$ & 35.8 & 41.4 & 30.8 & 0.363 \\
\hline Secondary education & 50.0 & 44.3 & 55.1 & \\
\hline University degree & 13.5 & 12.9 & 14.1 & \\
\hline Postgraduate & 0.7 & 1.4 & 0 & \\
\hline \multicolumn{5}{|l|}{ Family income (\%) } \\
\hline$<450$ USD & 68.9 & 68.6 & 69.2 & 0.346 \\
\hline 450-1000 USD & 22.3 & 25.7 & 19.2 & \\
\hline$>1000$ USD & 8.8 & 5.7 & 11.5 & \\
\hline Parental support for PA (range 0-4, mean (SD)) & $1.5(1.03)$ & $1.5(1.05)$ & $1.6(1.01)$ & 0.691 \\
\hline TV available in room (\% yes) & 59.5 & 60.0 & 59.0 & 0.899 \\
\hline Computer in room (\% yes) & 76.4 & 78.6 & 74.4 & 0.547 \\
\hline Videogame console ownership (\% yes) & 18.2 & 12.9 & 23.1 & 0.108 \\
\hline TVs per house (mean (SD)) & $1.8(0.94)$ & $1.8(0.90)$ & $1.9(0.97)$ & 0.748 \\
\hline Mobile phone ownership (\% yes) & 51.4 & 57.1 & 46.2 & 0.182 \\
\hline Portable videogame console ownership (\% yes) & 83.1 & 78.6 & 87.2 & 0.163 \\
\hline \multicolumn{5}{|l|}{ Neighborhood environment } \\
\hline $\begin{array}{l}\text { Collective efficacy (range 1-5, mean (SD)) } \\
\text { (a) }\end{array}$ & $3.5(0.66)$ & $3.5(0.72)$ & $3.5(0.60)$ & 0.615 \\
\hline Walkability (range $0-4$, mean (SD)) & $1.6(0.59)$ & $1.6(0.64)$ & $1.6(0.55)$ & 0.907 \\
\hline Distance to places (range 0-4, mean (SD)) & $2.4(2.17,2.5)$ & $2.4(2.10,2.67$ & $2.4(2.09,2.61$ & 0.847 \\
\hline
\end{tabular}

\section{Sample characteristics}

Details about the characteristics of the sample are shown in Table 1 . The overall age of the sample was $10.0 \pm 0.82$ years. About 7 out of 10 children were overweight or obese. Only two descriptive variables were significantly different between boys and girls. The motivation for PA was higher in girls ( $p=0.007$ ), while sports participation was more prevalent in boys $(\mathrm{p}<0.001)$ than girls. All school principals reported having school policies for PA promotion, but only 1 out of 6 schools had an established healthy lifestyle committee (Table 2). None of the school principals knew the PA recommendations for children. Only one school reported that more than $25 \%$ of the pupils attend sport or PA clubs. Basketball and football were the most common sports activities offered to children in schools. More details about the school-level variables are shown in Table 2.

Device-measured and self-reported physical behaviours

Details about the device-measured and self-reported 
Table 2.

\begin{tabular}{|c|c|}
\hline School-level variables & $\%$ \\
\hline Presence of school policies for PA & 100 \\
\hline Presence of school policies for healthy eating & 66.6 \\
\hline Established healthy lifestyle committee & 16.7 \\
\hline \multicolumn{2}{|l|}{ Proportion of pupils attending sport or PA clubs } \\
\hline Not available & 16.7 \\
\hline$<=24$ & 66.6 \\
\hline$>25 \%-49 \%$ & 16.7 \\
\hline \multicolumn{2}{|l|}{ Sports clubs (competitive and non-competitive) } \\
\hline Basketball & 66.6 \\
\hline Volleyball & 16.7 \\
\hline Football & 66.6 \\
\hline Gymnastics & \\
\hline Athletics & 33.3 \\
\hline 3 or more school breaks per day & 40 \\
\hline \multicolumn{2}{|l|}{ PE minutes per week } \\
\hline $45 \mathrm{~min} / \mathrm{week}$ & 66.6 \\
\hline $90 \mathrm{~min} /$ week & 16.7 \\
\hline $135 \mathrm{~min} /$ week & 16.7 \\
\hline \multicolumn{2}{|l|}{ Active transportation promotion strategies } \\
\hline Identify safe routes to school & 33.3 \\
\hline Presence of crossing guards at school & 33.3 \\
\hline Car free zone in surroundings & 16.7 \\
\hline Allow to bring bikes & 50.0 \\
\hline Allow to bring other small cycles & 16.7 \\
\hline Promote helmet or other safety measures for active transportation & 16.7 \\
\hline
\end{tabular}

physical behaviours of the sample are displayed in Table 3. Overall, the participants wore the accelerometer for $848.9 \pm 71.38$ minutes in an average day, with no differences between sexes $(\mathrm{p}=0.19)$. The participants spent $46.6 \pm 8.72 \%$ of their time in SB, $47.4 \pm 7.51 \%$ in LPA, $4.8 \pm 2.21 \%$ in MPA, $1.3 \pm 1.08 \%$ in VPA and $6.1 \pm 2.98 \%$ in MVPA. Boys spent more time in MPA (+15.2 min/day, $\mathrm{p}<0.001)$, VPA (+4.4 min/day, $\mathrm{p}=0.02)$ and MVPA $(+19.6 \mathrm{~min} / \mathrm{day}, \mathrm{p}<0.001)$ than girls. The mean sleeping time was $563.3 \pm 82.83 \mathrm{~min} /$ day $(9.4 \pm 1.38 \mathrm{~h} /$ day $)$ with no differences between boys and girls $(\mathrm{p}=0.57)$. Only $5.1 \%$ met the MVPA guidelines, and nearly half of the participants met the sleeping time recommendations. Based on self-reported data, $13.3 \%$ and $36.1 \%$ of the sample met the PA and screen recommendations for children, respectively.
Table 3.

\begin{tabular}{|c|c|c|c|c|}
\hline Variable & $\begin{array}{c}\text { Total } \\
(\mathrm{n}=148)\end{array}$ & $\begin{array}{c}\begin{array}{c}\text { Boys } \\
(\mathrm{n}=70)\end{array} \\
\end{array}$ & $\begin{array}{c}\text { Girls } \\
(\mathrm{n}=78)\end{array}$ & $\mathbf{p}$ \\
\hline \multicolumn{5}{|l|}{ Objectively measured } \\
\hline Wear time (min/day, mean (SD)) & 848.9 (71.38) & $841.2(64.65)$ & 856.0 (76.66) & 0.19 \\
\hline \multicolumn{5}{|l|}{ Sedentary behaviour } \\
\hline Mean \% (SD) & $46.6(8.72)$ & $45.4(8.37)$ & $47.7(8.93)$ & 0.10 \\
\hline Median \% [IQR] & $45.4[40.51,52.01]$ & $44.3[39.98,51.65]$ & $46.6[40.96,52.71]$ & \\
\hline Mean (min/day) (SD) & 395.5 (81.67) & $380.98(71.61)$ & $408.7(88.16)$ & 0.32 \\
\hline Median (min/day) [IQR] & $382.6[337.0,450.0]$ & $376.3[334.4,429.2]$ & $392.0[343.7,462.4]$ & \\
\hline \multicolumn{5}{|l|}{ LPA } \\
\hline Mean \% (SD) & $47.4(7.51)$ & $47.3(7.35)$ & $47.4(7.69)$ & 0.98 \\
\hline Median \% [IQR] & $47.8[42.3,53.1]$ & $47.3[41.9,53.1]$ & $48.1[42.5,52.32]$ & \\
\hline Mean (min/day) (SD) & $402.2(72.54)$ & $398.6(71.3)$ & $405.3(73.9)$ & 0.56 \\
\hline Median (min/day) [IQR] & $407.6[347.6,454.9]$ & $395.4[345.0,454.9]$ & $415.2[348.8,457.7]$ & - \\
\hline \multicolumn{5}{|c|}{ a } \\
\hline Mean \% (SD) & $4.8(2.21)$ & $5.7(2.31)$ & $3.9(1.71)$ & \\
\hline Median \% [IQR] & $4.5[3.0,6.0]$ & $5.5[4.2,7.4]$ & $3.8[2.6,5.1]$ & $<0.001$ \\
\hline Mean (min/day) (SD) & $40.5(18.98)$ & $48.5(20.48)$ & $33.3(14.14)$ & \\
\hline Median (min/day) [IQR] & $37.9[27.3,51.0]$ & $43.3[36.1,62.3]$ & $33.2[23.4,41.0]$ & $<0.001$ \\
\hline \multicolumn{5}{|l|}{ VPA } \\
\hline Mean \% (SD) & $1.3(1.08)$ & $1.5(1.27)$ & $1.0(0.82)$ & \\
\hline Median \% [IQR] & $0.9[0.6,1.7]$ & $1.1[0.6,2.0]$ & $0.8[0.5,1.3]$ & 0.02 \\
\hline Mean (min/day) (SD) & $10.8(9.30)$ & $13.1(11.12)$ & $8.7(6.68)$ & - \\
\hline Median (min/day) [IQR] & $7.6[5.0,14.6]$ & $10.0[5.4,16.7]$ & $7.4[4.3,10.7]$ & 0.02 \\
\hline \multicolumn{5}{|l|}{ MVPA } \\
\hline Mean \% (SD) & $6.1(2.98)$ & $7.3(3.16)$ & $4.9(2.32)$ & - \\
\hline Median \% [IQR] & $5.6[3.82,7.91]$ & $7.3[4.86,8.82]$ & $4.8[3.23,6.65]$ & $<0.001$ \\
\hline Mean (min/day) (SD) & $51.3(25.69)$ & $61.6(28.18)$ & $42.0(19.04)$ & - \\
\hline Median (min/day) [IQR] & $46.8[33.0,64.8]$ & $58.3[40.3,78.0]$ & $41.3[28.3,53.6]$ & $<0.001$ \\
\hline \multirow{2}{*}{\multicolumn{5}{|c|}{ Sleeping time }} \\
\hline Mean (min/day) (SD) & $563.3(82.83)$ & $569.7(89.47)$ & & \\
\hline Median (min/day) [IQR] & $552.5[512.1,601.0]$ & $556.1[515.7,616.9]$ & $550.0[503.1,603.0]$ & 0.57 \\
\hline Meeting MVPA guidelines (\%) & 5.1 & 8.0 & 2.4 & 0.11 \\
\hline Meeting Sleeping guidelines (\%) & 46.2 & 48.0 & 44.6 & 0.667 \\
\hline \multicolumn{5}{|l|}{$\begin{array}{l}\text { Self-reported } \\
\end{array}$} \\
\hline Physically active days (mean (SD)) & $3.2(2.10)$ & $3.5(2.27)$ & $3.0(1.93)$ & 0.14 \\
\hline Meeting PA guidelines (\%) & 13.3 & 18.7 & 8.4 & 0.058 \\
\hline \multirow{3}{*}{$\begin{array}{l}\text { Meeting screen time guidelines (\%) } \\
\mathrm{TV}=2 \mathrm{~h} / \text { day }(\% \text { yes) } \\
\text { Videogames/computer }=2 \mathrm{~h} / \text { day } \\
\text { (\% yes) }\end{array}$} & 36.1 & 40.0 & 32.5 & 0.329 \\
\hline & 44.5 & 39.2 & 49.4 & 0.20 \\
\hline & 29.7 & 28.4 & 30.9 & 0.74 \\
\hline
\end{tabular}

(\% yes) physical activity; VPA: vigorous physical activity; MVPA: moderate-to-vigorous physical activity; PA: physical tivity; TV: television.

Accelerometer wearing time was longer during the week than weekend days in the total sample (Table 4). In relative terms based on wearing time, no differences were observed for SB in both boys and girls between week and weekend days. Only boys spent more time in LPA at the weekend than

\begin{tabular}{|c|c|c|c|c|c|c|c|c|c|}
\hline \multirow[t]{2}{*}{ Variable } & \multicolumn{3}{|c|}{$\begin{array}{c}\begin{array}{c}\text { Total } \\
(\mathrm{n}=148)\end{array} \\
\end{array}$} & \multicolumn{3}{|c|}{$\begin{array}{c}\text { Boys } \\
(\mathrm{n}=70)\end{array}$} & \multicolumn{3}{|c|}{$\begin{array}{c}\text { Girls } \\
(\mathbf{n}=78)\end{array}$} \\
\hline & Weekday & Weekend & $p$ & Weekday & Weekend & $p$ & Weekday & Weekend & $p$ \\
\hline Wear time (min/day) & $\begin{array}{l}879.0 \\
(75.1)\end{array}$ & $\begin{array}{c}769.5 \\
(100.3)\end{array}$ & $<0.001$ & $\begin{array}{c}868.4 \\
(68.98)\end{array}$ & $\begin{array}{c}767.7 \\
(90.18)\end{array}$ & $<0.001$ & $\begin{array}{l}888.6 \\
(79.5)\end{array}$ & $\begin{array}{c}771.1 \\
(109.1)\end{array}$ & $<0.001$ \\
\hline $\begin{array}{r}\text { Mean (\%) } \\
\text { (SD) } \\
\text { Median (\%) } \\
{[\text { IQR] }} \\
\text { Mean (min/day) } \\
\text { (SD) } \\
\text { Median (min/day) } \\
\text { [IQR] } \\
\end{array}$ & $\begin{array}{c}46.6 \\
(8.62) \\
45.3 \\
{[40.8,52.7]} \\
410.0 \\
(83.50) \\
400.8 \\
{[348.6,473.0]} \\
\end{array}$ & $\begin{array}{c}46.4 \\
(12.91) \\
44.6 \\
{[36.9,54.0]} \\
358.4 \\
(118.58) \\
333 \\
{[281.0,424.0]} \\
\end{array}$ & $\begin{array}{c}0.81 \\
- \\
<0.001 \\
-\end{array}$ & $\begin{array}{c}45.8 \\
(8.57) \\
45.1 \\
{[40.1,50.7]} \\
397.46 \\
(77.50) \\
385.2 \\
{[348.6,449.0]}\end{array}$ & $\begin{array}{c}43.9 \\
(11.69) \\
43.7 \\
{[35.5,50.8]} \\
336.3 \\
(97.04) \\
313.5 \\
{[272.5,400.0]} \\
\end{array}$ & $\begin{array}{c}- \\
<0.001 \\
-\end{array}$ & $\begin{array}{c}47.4 \\
(8.65) \\
46.8 \\
{[41.1,52.7]} \\
421.3 \\
(87.50) \\
409.5 \\
{[347.8,481.8]} \\
\end{array}$ & $\begin{array}{c}48.8 \\
(13.58) \\
46.8 \\
{[39.0,57.8]} \\
378.4 \\
(132.55) \\
367 \\
{[289.0,451.0]}\end{array}$ & 0.001 \\
\hline $\begin{array}{r}\text { Mean (\%) } \\
\text { (SD) } \\
\text { Median (\%) } \\
{[\text { IQR }]} \\
\text { Mean (min/day) } \\
\text { (SD) } \\
\text { Median (min/day) } \\
\text { [IQR] }\end{array}$ & $\begin{array}{c}47.1 \\
(7.53) \\
47.4 \\
{[42.0,52.2]} \\
414.6 \\
(75.01) \\
421.4 \\
{[365.8,469.8]}\end{array}$ & $\begin{array}{c}48.1 \\
(11.08) \\
49.5 \\
{[42.0,56.8]} \\
368.8 \\
(95.05) \\
372.8 \\
{[313.0,432.0]}\end{array}$ & $\begin{array}{c}0.23 \\
-\end{array}$ & $\begin{array}{c}46.7 \\
(7.62) \\
48.2 \\
{[43.5,52.2]} \\
406.1 \\
(74.07) \\
402.6 \\
{[357.4,464.8]}\end{array}$ & $\begin{array}{c}49.4 \\
(10.22) \\
50.3 \\
{[44.1,57.4]} \\
379.5 \\
(90.88) \\
381.5 \\
{[323.0,430.0]}\end{array}$ & $\begin{array}{c}0.016 \\
- \\
0.004 \\
-\end{array}$ & $\begin{array}{c}47.5 \\
(7.47) \\
47.1 \\
{[40.8,53.0]} \\
422.2 \\
(75.48) \\
435.7 \\
{[367.4,471.0]}\end{array}$ & $\begin{array}{c}46.8 \\
(11.72) \\
47.9 \\
{[39.5,56.8]} \\
359.1 \\
(98.21) \\
363 \\
{[305.0,434.5]}\end{array}$ & $<0.001$ \\
\hline $\begin{array}{r}\text { Mean (\%) } \\
\text { (SD) } \\
\text { Median (\%) } \\
\text { [IQR] } \\
\text { Mean (min/day) } \\
\text { (SD) } \\
\text { Median (min/day) } \\
\text { [IQR] } \\
\end{array}$ & $\begin{array}{c}4.9 \\
(2.21) \\
4.5 \\
{[3.0,6.0]} \\
43.3 \\
(19.53) \\
41 \\
{[29.6,53.8]} \\
\end{array}$ & $\begin{array}{c}4.2 \\
(3.03) \\
3.7 \\
{[2.1,5.9]} \\
32.7 \\
(23.91) \\
27.8 \\
{[15.5,44.5]} \\
\end{array}$ & $\begin{array}{c}- \\
<0.001 \\
-\end{array}$ & $\begin{array}{c}5.9 \\
(2.26) \\
5.9 \\
{[4.3,7.4]} \\
51.1 \\
(20.64) \\
51 \\
{[34.8,66.4]} \\
\end{array}$ & $\begin{array}{c}5.3 \\
(3.46) \\
5.1 \\
{[2.4,7.4]} \\
41.0 \\
(27.79) \\
33 \\
{[17.5,57.5]} \\
\end{array}$ & $<0.001$ & $\begin{array}{c}4.1 \\
(1.81) \\
4.2 \\
{[2.6,5.4]} \\
36.2 \\
(15.48) \\
37.0 \\
{[23,47.0]} \\
\end{array}$ & $\begin{array}{c}3.3 \\
(2.2) \\
2.8 \\
{[1.2,4 .]} \\
25.2 \\
(16.68) \\
24.0 \\
{[10.0,35.5]} \\
\end{array}$ & $\begin{array}{c}- \\
<0.001\end{array}$ \\
\hline $\begin{array}{r}\text { Mean (\%) } \\
\text { (SD) } \\
\text { Median (\%) } \\
{[\text { IQR }]} \\
\text { Mean (min/day) } \\
\text { (SD) } \\
\text { Median (min/day) } \\
{[\mathrm{IQR}]}\end{array}$ & $\begin{array}{c}1.3 \\
(1.09) \\
0.9 \\
{[0.53,1.63]} \\
11.2 \\
(9.57) \\
8.4 \\
{[5.0,14.0]} \\
\end{array}$ & $\begin{array}{c}1.3 \\
(1.77) \\
0.8 \\
{[0.18,1.55]} \\
9.6 \\
(13.22) \\
6.0 \\
{[1.5,13.0]} \\
\end{array}$ & $<0.001$ & $\begin{array}{c}1.6 \\
(1.26) \\
1.1 \\
{[0.64,2.25]} \\
13.8 \\
(11.35) \\
9.7 \\
{[5.8,19.2]} \\
\end{array}$ & $\begin{array}{c}1.4 \\
(1.74) \\
0.93 \\
{[0.26,1.84]} \\
10.9 \\
(14.02) \\
7.0 \\
{[2.0,14.0]} \\
\end{array}$ & 0.037 & $\begin{array}{c}1.0 \\
(0.82) \\
0.8 \\
{[0.47,1.23]} \\
8.9 \\
(6.90) \\
7.5 \\
{[4.4,12.0]} \\
\end{array}$ & $\begin{array}{c}1.1 \\
(1.79) \\
0.67 \\
{[0.14,1.24]} \\
8.4 \\
(12.40) \\
5.5 \\
{[1.0,9.0]} \\
\end{array}$ & 0.061 \\
\hline $\begin{array}{r}\text { Mean (\%) } \\
\text { (SD) } \\
\text { Median (\%) } \\
{[\mathrm{IQR}]} \\
\text { Mean (min/day) } \\
\text { (SD) } \\
\text { Median (min/day) } \\
{[\mathrm{IQR}]} \\
\end{array}$ & $\begin{array}{c}6.2 \\
(3.00) \\
5.9 \\
{[4.02,7.85]} \\
54.5 \\
(26.52) \\
50.8 \\
{[37.2,69.0]}\end{array}$ & $\begin{array}{c}5.5 \\
(4.08) \\
4.6 \\
{[2.56,8.09]} \\
42.3 \\
(32.06) \\
33.3 \\
{[19.0,60.5]}\end{array}$ & $<0.001$ & $\begin{array}{c}7.4 \\
(3.12) \\
7.3 \\
{[5.0,9.25]} \\
64.9 \\
(28.57) \\
63.8 \\
{[41.25,84.67]}\end{array}$ & $\begin{array}{c}6.7 \\
(4.48) \\
5.8 \\
{[2.93,10.05]} \\
51.9 \\
(36.54) \\
46.0 \\
{[22.0,75.0]}\end{array}$ & $<0.001$ & $\begin{array}{c}5.1 \\
(2.42) \\
4.9 \\
{[3.08,6.78]} \\
45.1 \\
(20.58) \\
44.8 \\
{[27.67,59.0]}\end{array}$ & $\begin{array}{c}4.4 \\
(3.37) \\
3.7 \\
{[1.73,6.03]} \\
33.6 \\
(24.52) \\
30.0 \\
{[13.5,45.0]}\end{array}$ & $<0.001$ \\
\hline $\begin{array}{r}\text { Mean (min/day) } \\
\text { (SD) } \\
\text { Median (min/day) } \\
{[\mathrm{IQR}]} \\
\text { Meeting MVPA guidelines (\%) }\end{array}$ & $\begin{array}{c}\begin{array}{c}552.3 \\
(85.50) \\
543.5 \\
{[500.6,603.5]} \\
7.6\end{array} \\
\end{array}$ & $\begin{array}{c}570.9 \\
(96.10) \\
574.0 \\
{[503.0,622.0]} \\
16.5 \\
\end{array}$ & $\begin{array}{c}- \\
0.005 \\
0.015 \\
\end{array}$ & $\begin{array}{c}558.9 \\
(85.69) \\
549.0 \\
{[506.0,616.0]} \\
12.0 \\
\end{array}$ & $\begin{array}{c}565.3 \\
(103.94) \\
564.3 \\
{[497.0,620.5]} \\
26.7 \\
\end{array}$ & $\begin{array}{c}0.19 \\
0.023 \\
\end{array}$ & $\begin{array}{c}546.3 \\
(85.44) \\
535.4 \\
{[494.0,595.8]} \\
3.6 \\
\end{array}$ & $\begin{array}{c}\begin{array}{c}575.9 \\
(88.82) \\
576.5 \\
{[521.0,626.0]} \\
7.2\end{array} \\
\end{array}$ & $\begin{array}{l}0.017 \\
0.303\end{array}$ \\
\hline
\end{tabular}




\section{Correlates of moderate physical activity}

MPA was positively associated with being male, higher self-efficacy scores, outdoor time, sports participation, the presence of a school committee for promoting healthy lifestyle and proportion of pupils participating in sport/PA clubs at schools $(\mathrm{p}<0.10)$ (Table 5). Correlates negatively associated with MPA were age, screen time, distance to places and promotion of active transportation to/from school. For MPA, no significant home environment correlates were identified. All correlates that were significant in the fully adjusted model were positively associated with MPA: being male, selfefficacy and established healthy lifestyle committee at school (Table 6).

\section{Correlates of vigorous physical activity}

In the initial model that included potential correlates, being male, self-efficacy scores, father's educational level and percentage of pupils' participation in sport/PA clubs at school were positively associated with VPA $(\mathrm{p}<0.10)$ (Table 5). On the other hand, BMI z-score and family income were negatively associated with VPA $(\mathrm{p}<0.10)$. Variables from the behavioural and neighbourhood domains were not associated with VPA. In the fully adjusted model, VPA was only associated with correlates from the demographic and psychological levels: sex, BMI z-score and self-efficacy (Table 6).

Correlates of moderate-to-vigorous physical activity

The potential correlates positively associated with MVPA in the simple model were: being male, self-efficacy, sports participation, the presence of a healthy lifestyle committee at school and percentage of pupils' participation in sport/PA clubs at school $(\mathrm{p}<0.10)$ (Table 5). Whereas, negative associations were observed between distance to places and promotion strategies for active transportation to/from school with MVPA $(p<0.10)$. Only sex, self-efficacy and presence of a healthy lifestyle committee at school remained significantly associated with MVPAin the fully adjusted model (Table 6).

\section{Correlates of sleeping time}

When modelling for assessing potential correlates, age, portable videogame ownership (both negative), active transportation to/from school, TVs per house, minutes of PE per week (all positive) were associated $(\mathrm{p}<0.10)$ with sleeping time (Table 5). The final model showed that age, portable videogame ownership (both negative) and PE minutes per week (positive) were associated with sleeping time (Table 6).

\section{Discussion}

This study assessed the association between potential individual, social and environmental correlates with different intensities of PA, SB and sleeping time as measured with an accelerometer in children from 9 to 11 years in Carahue, Chile. Also, the study included the comparison of physical behaviours according to sex and day of the week (weekday/ weekend). Physical inactivity was highly prevalent (objectively measured: $94.9 \%$; self-reported: $86.7 \%$ ) in the sample. Children tended to be more physically active during week than weekend days with boys accumulating more minutes per day in MPA, VPA and MVPA than girls. No differences were observed in sedentary time between boys and girls, and only 36.1\% met the screen-time guidelines. Sleeping time was similar between boys and girls on an average day, but girls slept more in the weekend than weekdays. Each behaviour was partially explained by diverse variables from different levels or domains, supporting that there is not a specific set of factors that may explain physical behaviours in children.

Children from this study were less sedentary and less physically active than children of similar age from other countries (Chaput et al., 2015). However, the mean sleeping time (9.4 h/day) was comparable with figures recorded in Australia, Canada, South Africa and the UK (Chaput et al., 2015). Sex and age are two commonly reported correlates of physical behaviours in children. Our study, in line with these previous reports, showed disparities in most physical behaviours between sexes, except for LPA and sleeping time. Sedentary time was larger in girls, and time spent in MPA, VPA and MVPA were higher in boys as shown in most international studies (Bringolf-Isler et al., 2018; Herman, Sabiston, Mathieu, Tremblay, \& Paradis, 2015; Kavanaugh, Moore, Hibbett, \& Kaczynski, 2015; King et al., 2011; Ortega et al., 2018). Age was positively correlated with sedentary time but negatively with LPA and sleeping time. Although we included a narrow age range for this study, large differences per every increasing year were observed for each of the three behaviours. These findings suggest that the transition to more sedentary and less active lifestyles may start from earlier stages. A recent study in a younger sample has even shown that this transition can be observed in children aged 6 to 9 (Jago et al., 2018), reinforcing the need for strengthening preventive and promotion strategies from earlier stages.

Another commonly reported correlate of physical behaviours at the individual level is the nutritional status (Baena, Vega, \& Ramírez, 2018). In our study, the BMI zscore was only negatively associated with VPA, while other studies have reported associations between nutritional status with sedentary or screen time (positive) (Herman et al., 2015; King et al., 2011) and MVPA (negative) (King et al., 2011). Longitudinal studies are scarce in this age group to explain a uni or bi-directional association with health outcomes, but strong evidence in adults have shown the relevance of maintaining a healthy weight to prevent the rise of non-communicable diseases (Webber et al., 2012). This sample was particularly overweight and obese, therefore, more aggressive multisectoral strategies are needed to prevent and restraint this unhealthy condition at very early stages.

Among the psychological correlates, only self-efficacy was positively associated with MPA, VPA and MVPA. Even though self-efficacy is commonly reported as a correlate or determinant of PA(Kavanaugh et al., 2015), few studies have investigated the longitudinal relationship between this psychological variable and either PA or ST. Recently, Forthofer et al. (2017) found that self-efficacy was protective against declines in device-measured PA, but only in girls. Another study showed that self-efficacy predicts selfreported PA in both girls and boys (Li et al., 2018). Also, they reported that specific domains of self-efficacy, such as the 
predilection for PA, might protect against declines in PA and increases in ST during schools years. These findings are promissory as building self-efficacy with focus on predilection or preference for being active through positive environments and experiences may enhance PA and potentially decrease ST in school-aged children.

In the final fully adjusted, one behavioural correlate was identified in this study: total screen time. Time spent watching TV or playing videogames was positively associated with SB and negatively related with LPA in line with similar findings reported by Herman et al. (2015). It is relevant to note that other well-documented behavioural correlates such sport participation (Kokko et al., 2018; Wilkie et al., 2018) or active commuting (King et al., 2011; Wilkie et al., 2018) were not significant in the fully adjusted model, but they were identified as potential correlates in the simple models. These outcomes reinforce theories about the complex and context-dependent interactions of individual, social and environmental correlates for physical behaviours (Atkin et al., 2016).

Regarding the home environment, family income was positively related with $S B$, and negatively related with LPA. Parent support for PA was only positively associated with LPA and inversely associated with SB. These associations suggest that strategies for promoting PAby including parents in the process have the potential to reduce $\mathrm{SB}$, but these may not be enough for improving MVPA by itself. Therefore, more active and meaningful approaches for caregivers are needed in programs to achieve positive results in multicomponent interventions. In line with the literature (Hale \& Guan, 2015), our study showed that those children who own a portable videogame console affected their sleeping time negatively. This reinforces the call for reducing screen time, not only TV but different modalities such as portable videogames to promote good physical and mental health in children.

Interestingly, the unique physical behaviour that was influenced by the neighbourhood environment was SB. A potential explanation may be that closest places reported by parents were those that do not necessarily require engagement in MVPA, but LPA, such as stores and other services. In tone with our findings, a study from Switzerland showed that boys who lived in neighbourhoods with dead ends, and both low street and greenspace density showed less time spent in SB than their peers, suggesting that built environment features have also influences over time spent in SB in children (Bringolf-Isler et al., 2018).

At school level, the presence of a healthy lifestyle committee at school was positively associated with MVPA. The implementation of these committees that include a responsible, collaborators and written principles or guidelines for promoting healthier lifestyles may be a low-cost strategy for starting a change in school communities. Also, a novel finding was that children who engaged in more minutes of PE per week tended to sleep more. This highlights the relevance of $\mathrm{PE}$ in other transverse aspects for comprehensive health. Despite school environment showed important potential benefits, home and neighbourhoods' environments should also be included in local and government strategies to increase PA participation.

\section{Strengths and limitations}

To the best of our knowledge is the first study reporting device-measured physical activity, sedentary behaviour and sleeping time in Chilean children. This study included a socioeconomically representative sample from urban and rural areas of Carahue. Also, we collected data at individual, family and school levels to include an extensive list of potential correlates. However, the study presented some limitations that should be considered when translating results. The crosssectional design limits the establishment of a causal relationship between correlates and behaviours. Also, low wearing compliance was observed for the accelerometer, affecting the final number of participants due to the strict protocol used in the study. However, no differences were observed on demographic characteristics between those with enough and insufficient accelerometer data.

\section{Conclusion}

Physical inactivity was highly prevalent in children from Carahue, but boys were more physically active than girls. Overall, no differences were observed in the time spent in sedentary activities and sleeping between boys and girls. Variables from different levels explained each behaviour, reinforcing the need for multilevel strategies for promoting and helping to ensure healthier lifestyles in children. Coordinated efforts from different sectors must be implemented to ensure opportunities for children to be more active not only in school environments but also in out-ofschool hours, particularly on weekends. Therefore, urban planning, social development and transport among other sectors are called to be part of these actions. Further prospective studies are needed to identify potential mechanisms for these behaviours to conduct more effective strategies in this scenario. In the meantime, governments should ensure evaluation of current strategies and practices to identify relevant aspects such as reach, effectiveness, adoption, implementation and maintenance for optimising investments of resources.

\section{Acknowledgements}

The authors would like to thank the participants, caregivers, teachers and school principals for collaborating with this study. This study was funded by CONICYT FONDECYT 11160720 and the Ministry of Education of Chile and Universidad de La Frontera throughout the Institutional Improvement Plan UNETE, Universidad es Territorio, FRO 1301(UNT14-008).

Special thanks to UFRO Activate research team for their assistance.

\section{Authors' contribution}

NAF conceptualized the manuscript and analyzed data; NAF, DCP and PMF interpreted data and summarized findings; NAF drafted the manuscript; all authors critically reviewed the manuscript; all authors have read and approved the final version of the manuscript and agree with the order of presentation of the authors. 


\section{Conflict of interest}

The authors declare that they have no competing interests.

\section{References}

Aadland, E., Andersen, L. B., Anderssen, S. A., \& Resaland, G. K. (2018). A comparison of 10 accelerometer non-wear time criteria and logbooks in children. BMC Public Health, 18(1), 323. doi:10.1186/s12889-018-5212-4

Aguilar-Farias, N., Cortinez-O’Ryan, A., Sadarangani, K. P., Von Oetinger, A., Leppe, J., Valladares, M., . . . Cristi-Montero, C. (2016). Results From Chile's 2016 Report Card on Physical Activity for Children and Youth. J Phys Act Health, 13(11 Suppl 2), S117-S123. doi:10.1123/jpah.2016-0314

Aguilar-Farias, N., Martino-Fuentealba, P., Carcamo-Oyarzun, J., Cortinez-O’Ryan, A., Cristi-Montero, C., Von Oetinger, A., \& Sadarangani, K. P. (2018). A regional vision of physical activity, sedentary behaviour and physical education in adolescents from Latin America and the Caribbean: results from 26 countries. Int J Epidemiol, 47(3), 976-986. doi:10.1093/ije/dyy033

Aguilar-Farias, N., Miranda-Marquez, S., Sadarangani, K. P., Martino-Fuentealba, P., Cristi-Montero, C., CarcamoOyarzun, J., . . . Cortinez-O’Ryan, A. (2018). Results from Chile's 2018 Report Card on Physical Activity for Children and Youth. J Phys Act Health, 15(S2), S331-S332. doi:10.1123/ jpah.2018-0553

Atkin, A. J., van Sluijs, E. M. F., Dollman, J., Taylor, W. C., \& Stanley, R. M. (2016). Identifying correlates and determinants of physical activity in youth: How can we advance the field? Prev Med, 87, 167-169. doi:10.1016/j.ypmed.2016.02.040

Aubert, S., Barnes, J. D., Aguilar-Farias, N., Cardon, G., Chang, C. K., Delisle Nystrom, C., . . . Tremblay, M. S. (2018). Report Card Grades on the Physical Activity of Children and Youth Comparing 30 Very High Human Development Index Countries. JPhys Act Health, 15(S2), S298-S314. doi:10.1123/jpah.20180431

Baena, A. C. M., Vega, D. M., \& Ramírez, J. V. (2018). Factores predictores de la actividad física en escolares españoles de acuerdo a su estado de peso. Retos: nuevas tendencias en educación física, deporte y recreación(33), 74-80.

Barreira, T. V., Schuna, J. M., Jr., Mire, E. F., Katzmarzyk, P. T., Chaput, J. P., Leduc, G., \& Tudor-Locke, C. (2015). Identifying children's nocturnal sleep using 24-h waist accelerometry. Med Sci Sports Exerc, 47(5), 937-943. doi:10.1249/ MSS.0000000000000486

Bringolf-Isler, B., de Hoogh, K., Schindler, C., Kayser, B., Suggs, L. S., Dossegger, A., . . . Group, S. S. (2018). Sedentary Behaviour in Swiss Children and Adolescents: Disentangling Associations with the Perceived and Objectively Measured Environment. Int J Environ Res Public Health, 15(5). doi:10.3390/ijerph15050918

Carson, V., Tremblay, M. S., Spence, J. C., Timmons, B. W., \& Janssen, I. (2013). The Canadian Sedentary Behaviour Guidelines for the Early Years (zero to four years of age) and screen time among children from Kingston, Ontario. Paediatr Child Health, 18(1), 25-28.

Chaput, J. P., Gray, C. E., Poitras, V. J., Carson, V., Gruber, R., Olds, T., .. . Tremblay, M. S. (2016). Systematic review of the relationships between sleep duration and health indicators in school-aged children and youth. Appl Physiol Nutr Metab, 41(6 Suppl 3), S266-282. doi:10.1139/apnm-2015-0627

Chaput, J. P., Katzmarzyk, P. T., LeBlanc, A. G., Tremblay, M. S.,
Barreira, T. V., Broyles, S. T., . . . Group, I. R. (2015). Associations between sleep patterns and lifestyle behaviors in children: an international comparison. Int J Obes Suppl, 5(Suppl 2), S59-65. doi:10.1038/ijosup.2015.21

de Onis, M., Onyango, A. W., Borghi, E., Siyam, A., Nishida, C., \& Siekmann, J. (2007). Development of a WHO growth reference for school-aged children and adolescents. Bull World Health Organ, 85(9), 660-667.

Dean, A. G., Sullivan, K. M., \& Soe, M. M. (2013, 06-04-2013). OpenEpi: Open Source Epidemiologic Statistics for Public Health. 3.01. Retrieved from https://www.openepi.com

Evenson, K. R., Catellier, D. J., Gill, K., Ondrak, K. S., \& McMurray, R. G. (2008). Calibration of two objective measures of physical activity for children. J Sports Sci, 26(14), 15571565. doi:10.1080/02640410802334196

Forthofer, M., Dowda, M., O’Neill, J. R., Addy, C. L., McDonald, S., Reid, L., \& Pate, R. R. (2017). Effect of Child Gender and Psychosocial Factors on Physical Activity From Fifth to Sixth Grade. J Phys Act Health, 14(12), 953-958. doi:10.1123/ jpah.2016-0487

Frank, L. D., Saelens, B. E., Chapman, J., Sallis, J. F., Kerr, J., Glanz, K., . . . Cain, K. L. (2012). Objective assessment of obesogenic environments in youth: geographic information system methods and spatial findings from the Neighborhood Impact on Kids study. Am J Prev Med, 42(5), e47-55. doi:10.1016/j.amepre.2012.02.006

Hale, L., \& Guan, S. (2015). Screen time and sleep among schoolaged children and adolescents: a systematic literature review. Sleep medicine reviews, 21, 50-58.

Herman, K. M., Sabiston, C. M., Mathieu, M. E., Tremblay, A., \& Paradis, G. (2015). Correlates of sedentary behaviour in 8- to 10-year-old children at elevated risk for obesity. Appl Physiol Nutr Metab, 40(1), 10-19. doi:10.1139/apnm-2014-0039

Jago, R., Salway, R., Lawlor, D. A., Emm-Collison, L., Heron, J., Thompson, J. L., \& Sebire, S. J. (2018). Profiles of children's physical activity and sedentary behaviour between age 6 and 9: a latent profile and transition analysis. Int J Behav Nutr Phys Act, 15(1), 103. doi:10.1186/s12966-018-0735-8

Katzmarzyk, P. T., Barreira, T. V., Broyles, S. T., Champagne, C. M., Chaput, J. P., Fogelholm, M., . . Church, T. S. (2013). The International Study of Childhood Obesity, Lifestyle and the Environment (ISCOLE): design and methods. BMC Public Health, 13, 900. doi:10.1186/1471-2458-13-900

Kavanaugh, K., Moore, J. B., Hibbett, L. J., \& Kaczynski, A. T. (2015). Correlates of subjectively and objectively measured physical activity in young adolescents. Journal of Sport and Health Science, 4(3), 222-227. doi:https://doi.org/10.1016/ j.jshs.2014.03.015

King, A. C., Parkinson, K. N., Adamson, A. J., Murray, L., Besson, H., Reilly, J. J., . . . Gateshead Millennium Study Core, T. (2011). Correlates of objectively measured physical activity and sedentary behaviour in English children. Eur J Public Health, 21(4), 424-431. doi:10.1093/eurpub/ckq104

Kline, P. (2013). Handbook of Psychological Testing: Taylor \& Francis.

Kokko, S., Martin, L., Geidne, S., Van Hoye, A., Lane, A., Meganck, J., . . . Koski, P. (2018). Does sports club participation contribute to physical activity among children and adolescents? A comparison across six European countries. Scand J Public Health, 1403494818786110. doi:10.1177/1403494818786110

Li, Y. C., Joshi, D., King-Dowling, S., Hay, J., Faught, B. E., \& Cairney, J. (2018). The longitudinal relationship between generalized self-efficacy and physical activity in school-aged children. European journal of sport science, 18(4), 569-578. 
doi:10.1080/17461391.2018.1430852

Motl, R. W., Dishman, R. K., Trost, S. G., Saunders, R. P., Dowda, M., Felton, G., . . Pate, R. R. (2000). Factorial validity and invariance of questionnaires measuring social-cognitive determinants of physical activity among adolescent girls. Prev Med, 31(5), 584-594.

Mullan, E., Markland, D., \& Ingledew, D. K. (1997). A graded conceptualisation of self-determination in the regulation of exercise behaviour: Development of a measure using confirmatory factor analytic procedures. Personality and Individual Differences, 23(5), 745-752.

Okely, A. D., Ghersi, D., Hesketh, K. D., Santos, R., Loughran, S. P., Cliff, D. P., . . Tremblay, M. S. (2017). A collaborative approach to adopting/adapting guidelines - The Australian 24 Hour Movement Guidelines for the early years (Birth to 5 years): an integration of physical activity, sedentary behavior, and sleep. BMC Public Health, 17(Suppl 5), 869. doi:10.1186/ s12889-017-4867-6

Ortega, F. Z., Jiménez, J. L. U., Molero, P. P., Valero, G. G., Sánchez, M. C., \& Cuberos, R. C. (2018). Niveles de actividad física en alumnado de Educación Primaria de la provincia de Granada. Retos: nuevas tendencias en educación física, deporte y recreación(34), 218-221.

Poitras, V. J., Gray, C. E., Borghese, M. M., Carson, V., Chaput, J. P., Janssen, I., . . . Tremblay, M. S. (2016). Systematic review of the relationships between objectively measured physical activity and health indicators in school-aged children and youth. Appl Physiol Nutr Metab, 41(6 Suppl3), S197-239. doi:10.1139/ apnm-2015-0663

Ravens-Sieberer, U., Erhart, M., Rajmil, L., Herdman, M., Auquier, P., Bruil, J., . . European, K. G. (2010). Reliability, construct and criterion validity of the KIDSCREEN-10 score: a short measure for children and adolescents' well-being and healthrelated quality of life. Quality of life research : an international journal of quality of life aspects of treatment, care and rehabilitation, 19(10), 1487-1500. doi:10.1007/s11136-0109706-5

Rosenberg, D., Ding, D., Sallis, J. F., Kerr, J., Norman, G. J., Durant, N., . . Saelens, B. E. (2009). Neighborhood Environment Walkability Scale for Youth (NEWS-Y): reliability and relationship with physical activity. Prev Med, 49(2-3), 213218. doi:10.1016/j.ypmed.2009.07.011

Saelens, B. E., Sallis, J. F., Frank, L. D., Couch, S. C., Zhou, C., Colburn, T., ... Glanz, K. (2012). Obesogenic neighborhood environments, child and parent obesity: the Neighborhood Impact on Kids study. Am J Prev Med, 42(5), e57-64. doi:10.1016/j.amepre.2012.02.008

Sallis, J. F., Cervero, R. B., Ascher, W., Henderson, K. A., Kraft, M. K., \& Kerr, J. (2006). An ecological approach to creating active living communities. Annu Rev Public Health, 27, 297322. doi:10.1146/annurev.publhealth.27.021405.102100

Sampasa-Kanyinga, H., Standage, M., Tremblay, M. S., Katzmarzyk, P. T., Hu, G., Kuriyan, R., . . . Chaput, J. P. (2017). Associations between meeting combinations of 24-h movement guidelines and health-related quality of life in children from 12 countries. Public Health, 153, 16-24. doi:10.1016/ j.puhe.2017.07.010

Sampson, R. J., Raudenbush, S. W., \& Earls, F. (1997). Neighborhoods and violent crime: a multilevel study of collective efficacy. Science, 277(5328), 918-924.

Saunders, T. J., Gray, C. E., Poitras, V. J., Chaput, J. P., Janssen, I., Katzmarzyk, P. T., ... Carson, V. (2016). Combinations of physical activity, sedentary behaviour and sleep: relationships with health indicators in school-aged children and youth. Appl
Physiol Nutr Metab, 41(6 Suppl 3), S283-293. doi:10.1139/ apnm-2015-0626

Saunders, T. J., \& Vallance, J. K. (2017). Screen Time and Health Indicators Among Children and Youth: Current Evidence, Limitations and Future Directions. Appl Health Econ Health Policy, 15(3), 323-331. doi:10.1007/s40258-016-0289-3

Sterdt, E., Liersch, S., \& Walter, U. (2014). Correlates of physical activity of children and adolescents: A systematic review of reviews. Health Education Journal, 73(1), 72-89.

Streiner, D. L. (2003). Starting at the beginning: an introduction to coefficient alpha and internal consistency. J Pers Assess, 80(1), 99-103. doi:10.1207/S15327752JPA8001_18

The KIDSCREEN Group Europe. (2006). The KIDSCREEN Questionnaires - Quality of life questionnaires for children and adolescents. Lengerich: Pabst Science Publishers.

Tremblay, M. S., Barnes, J. D., González, S. A., Katzmarzyk, P. T., Onywera, V. O., Reilly, J. J., \& Tomkinson, G. R. (2016). Global Matrix 2.0: Report Card Grades on the Physical Activity of Children and Youth Comparing 38 Countries. J Phys Act Health, 13(11 Suppl 2), S343-S366. doi:10.1123/jpah.20160594

Tremblay, M. S., Carson, V., Chaput, J. P., Connor Gorber, S., Dinh, T., Duggan, M., . . . Zehr, L. (2016). Canadian 24-Hour Movement Guidelines for Children and Youth: An Integration of Physical Activity, Sedentary Behaviour, and Sleep. Appl Physiol Nutr Metab, 41(6 Suppl 3), S311-327. doi:10.1139/ apnm-2016-0151

Tudor-Locke, C., Barreira, T. V., Schuna, J. M., Jr., Mire, E. F., Chaput, J. P., Fogelholm, M., . . . Group, I. R. (2015). Improving wear time compliance with a 24-hour waist-worn accelerometer protocol in the International Study of Childhood Obesity, Lifestyle and the Environment (ISCOLE). Int J Behav Nutr Phys Act, 12, 11. doi:10.1186/s12966-015-0172-x

U.S. Centers for Disease Control and Prevention. (2017). Youth Risk Behavior Surveillance System(YRBSS). Retrieved from https://www.cdc.gov/healthyyouth/data/yrbs/index.htm

Webber, L., Kilpi, F., Marsh, T., Rtveladze, K., Brown, M., \& McPherson, K. (2012). High rates of obesity and noncommunicable diseases predicted across Latin America. PloS one, 7(8), e39589. doi:10.1371/journal.pone.0039589

Wilkie, H. J., Standage, M., Gillison, F. B., Cumming, S. P., \& Katzmarzyk, P. T. (2018). Correlates of intensity-specific physical activity in children aged 9-11 years: a multilevel analysis of UK data from the International Study of Childhood Obesity, Lifestyle and the Environment. BMJ Open, 8(2), e018373. doi:10.1136/bmjopen-2017-018373

Williamson, D. A., Champagne, C. M., Harsha, D. W., Han, H., Martin, C. K., Newton, R. L., Jr., . . Ryan, D. H. (2012). Effect of an environmental school-based obesity prevention program on changes in body fat and body weight: a randomized trial. Obesity, 20(8), 1653-1661. doi:10.1038/oby.2012.60

World Health Organization. (2010). Global recommendations on physical activity for health. Retrieved from Geneva, Switzerland:

Yao, C. A., \& Rhodes, R. E. (2015). Parental correlates in child and adolescent physical activity: a meta-analysis. Int J Behav Nutr Phys Act, 12(1), 10. doi:10.1186/s12966-015-0163-y

Zhu, Z., Chen, P., \& Zhuang, J. (2013). Intensity classification accuracy of accelerometer-measured physical activities in Chinese children and youth. Res Q Exerc Sport, 84 Suppl 2, S411. doi:10.1080/02701367.2013.850919 